Lepr. Rev. (1969) 40, $117-120$

\title{
Hydrotherapy as a Method of Treatment for Contracted Fingers*
}

\author{
E. P. FRITSCHI \\ Superintendent and Surgeon, \\ The Leprosy Mission Hospital, Vadathorasalur, S. Arcot District, Madras State, S. India
}

The author reports promising preliminary results from the use of hydrotherapy followed by splinting in the treatment of contracture of the fingers in leprosy patients. The method is described in detail.

The correction of deformity of the hand which results from paralysis of the intrinsic musculature presents no great problem, provided the joints are mobile. The aim of the physiotherapist is to prevent contractures developing and to restore full mobility in fingers which have already become contracted. The methods at present available for this purpose include wax therapy, massage, and passive and active or dynamic splinting. During a brief stay in our institution, Miss Christianne Capiau of Belgium suggested the use of warm water as a means of releasing these contractures. She demonstrated a remarkable improvement in one week in a badly contracted hand. Following up her suggestion, we present this preliminary paper on our early observations of hydrotherapy in the treatment of contractures.

\section{MATERIALS AND METHODS}

Patients with claw hands showing skin contracture of the proximal interphalangeal joints were selected. The contracture angles of these joints were measured by passively stretching them by hand to their maximum. The same observer made the consecutive measurements in each case so that the individual variation in the force used in extension applied to the finger was minimal. The surgeon then examined each finger and recorded his opinion of the nature of the contracture, i.e. skin contracture, collateral

*Received for publication 13 January, 1969. ligament, or joint ankylosis. Fingers with obvious joint contracture, ankylosis, or other kinds of damage were excluded from the study.

The differentiation between skin contracture and capsular contracture is possible within certain limits. It is easy to ascertain the presence of a skin contracture, as the tightness can be felt on extending the proximal interphalangeal joint with the metacarpo-phalangeal joint fixed. It is not possible to say whether the skin is partially or wholly responsible for the contracture. Ankylosis is of two kinds, fibrous and bony. The former usually allows a very small range of movement of a few degrees. Bony ankylosis, of course, does not permit of any movement.

The patient's hand is immersed in a basin of warm water at a temperature not exceeding $45^{\circ} \mathrm{C}$ (app. $112^{\circ} \mathrm{F}$ ); the therapist gently massages the finger joints during the time of immersion, especially the skin on the anterior aspect, in such a manner as to encourage extension of the joint. Great care has to be exercised to prevent cracking of the anterior skin due to over enthusiasm. The treatment is continued for $10 \mathrm{~min}$, after which the hand is removed, dried, and the angles measured again; the pre- and post-treatment angles are recorded on a graph. The finger is then immediately immobilized in a cylinder of plaster of Paris, so maintaining the post-therapy angle. In our earlier cases these treatments were performed daily, but later it was found better to leave the fingers in the 


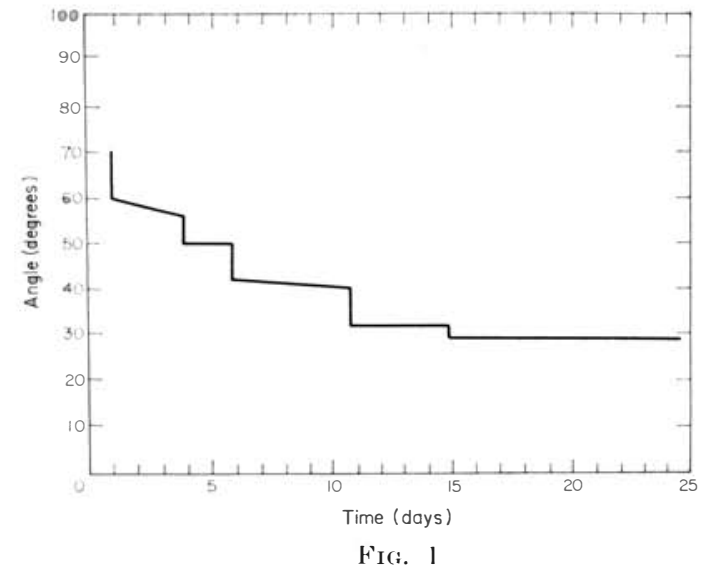

plaster for 2 days in order to allow for adaptation of the deeper layers of the skin to the new angle permitted by the softening of the cuticle.

\section{RESULTS}

Fig. 1 shows a typical record of a patient. The improvement obtained during one treatment is recorded on the same date. The graph, therefore, progresses in steps, each day's advance being maintained by plaster spliniting between treatments.

Table 1 shows the number of degrees of improvement noted during the first week and the second week of treatment, and in the last column the combined improvement in 2 weeks. The average improvement during the first week is $14.8^{\circ}$, with a range of $40^{\circ}$ to $-5^{\circ}$ ( S.D. $8.1^{\circ}$ ), and during the second week $7.4^{\circ}$, with a range $20^{\circ}$ to $0^{\circ}$ (s.D. $4.2^{\circ}$ ).

\section{COMPLICATIONS}

No blisters due to burns from the hot water were seen. Two patients, however, developed blisters on the dorsum of the fingers and on the middle segment pulp, but these were typical pressure blisters. One of these patients was an early case not included in this series. The other is case M, whose treatment had to be suspended. In one of these fingers the pressure blister was full skin thickness, but in the others it was superficial and soon desquamated, leaving nor mal skin. The technician who applied these splints was, in each case, an experienced person
TABILE 1

\begin{tabular}{|c|c|c|c|c|}
\hline Patient & $\begin{array}{l}\text { Initial } \\
\text { con- } \\
\text { tracture } \\
\text { angle }\end{array}$ & $\begin{array}{l}\text { Imp. } \\
\text { during } \\
\text { first } \\
\text { week }\end{array}$ & $\begin{array}{l}\text { Imp. } \\
\text { during } \\
\text { second } \\
\text { week }\end{array}$ & $\begin{array}{l}\text { Total } \\
\text { imp. } \\
\text { during } \\
2 \text { weeks }\end{array}$ \\
\hline \multirow[t]{3}{*}{$\mathrm{V}$} & 25 & 5 & 10 & 15 \\
\hline & 35 & 5 & 10 & 15 \\
\hline & 25 & 5 & 10 & 15 \\
\hline \multirow[t]{3}{*}{$P$} & 20 & 15 & 0 & 15 \\
\hline & 20 & 10 & 10 & 20 \\
\hline & 40 & 10 & 0 & 10 \\
\hline \multirow[t]{2}{*}{. $\mathrm{I}$} & 35 & 10 & - & - \\
\hline & 30 & 20 & - & - \\
\hline \multirow[t]{4}{*}{$v$} & 30 & 20 & 10 & 30 \\
\hline & 30 & 20 & 10 & 30 \\
\hline & 50 & 25 & 5 & 30 \\
\hline & 35 & 5 & 10 & 15 \\
\hline \multirow[t]{3}{*}{ L. } & 10 & 5 & 5 & 10 \\
\hline & 20 & 10 & 10 & 20 \\
\hline & 50 & 5 & 0 & 5 \\
\hline V & 40 & 20 & 5 & 25 \\
\hline \multirow{4}{*}{$\mathrm{J}$} & 70 & 15 & 10 & 25 \\
\hline & 55 & 20 & 15 & 35 \\
\hline & 45 & 20 & 0 & 20 \\
\hline & 80 & 40 & 0 & 40 \\
\hline \multirow[t]{3}{*}{ I } & 70 & 20 & 20 & 40 \\
\hline & 60 & 25 & 5 & 30 \\
\hline & 20 & 10 & 10 & 20 \\
\hline \multirow[t]{3}{*}{$\mathrm{J}$} & 35 & 15 & 15 & 30 \\
\hline & 40 & 20 & 20 & 40 \\
\hline & 50 & 30 & 10 & 40 \\
\hline \multirow[t]{2}{*}{$\mathrm{s}$} & 60 & 20 & 10 & 30 \\
\hline & 35 & 25 & 0 & 25 \\
\hline \multirow[t]{4}{*}{$\mathrm{MI}$} & 25 & 15 & 0 & 15 \\
\hline & 35 & 15 & 10 & 25 \\
\hline & 65 & 20 & 15 & 35 \\
\hline & 75 & 15 & 10 & 25 \\
\hline \multirow[t]{4}{*}{$\mathrm{S}$} & 25 & 5 & 5 & 10 \\
\hline & 25 & 5 & () & 5 \\
\hline & 25 & 15 & 0 & 15 \\
\hline & 15 & -5 & 0 & -5 \\
\hline Total & & $535^{\circ}$ & $250^{\circ}$ & $755^{\circ}$ \\
\hline Mean & & $14.8^{\circ}$ & $7.4^{\circ}$ & $22.2^{\circ}$ \\
\hline S.D. & & $8.1^{\circ}$ & $4.2^{\circ}$ & $10.3^{\circ}$ \\
\hline
\end{tabular}

who was regularly doing splintage without any mishaps. These 2 episodes therefore suggest the possibility: (a) that hydrotherapy may soften the skin too much, rendering it intolerant of pressure which it could normally withstand; and (b) that the large increase in the angle which follows the softening of the keratin layer during treatment, may cause an increase of pressure within the plaster after the skin dries, as a result of re-contraction of this layer. No other complications were noted. 


\section{DISCUSSION}

Water is used in physiotherapy for 2 purposes, viz. (1) as a medium of communicating heat to a part; and (2) as a means of eliminating gravity by immersing the whole patient in water and exercising the limbs under water.

Harris and Browne (1966) have drawn attention to the use of water as a softener of the keratin layer of the skin, and have emphasized its value in the prevention of recurrence of eczema in sweatless skin of the legs, and also in the treatment of fissures and callosities of the sole of the foot due to excessive dryness. The normal softness and suppleness of the skin of the hands depends on its capacity to sweat. Oil can, to some extent, artificially maintain this suppleness, but the normal oils of the skin are supplemented by the water secreted by sweat glands. The use of water is, therefore, a logical means of softening non-sweating skin. Our observations suggest that the method of action is as follows. The dry keratin layer is softened by the warm water and rendered more supple and elastic; the normal angle of improvement in a single treatment is 5 to $10^{\circ}$. If this new angle is maintained, then the deeper layers of the epidermis adapt to the new tension and the contracture progressively improves up to the limit determined by the deeper fibrous tissues such as the capsular ligaments. In the finger which showed $40^{\circ}$ improvement in the first week, there was no improvement in the second week. We feel that the figure for the first week represents the improvement due to release of the skin contracture, and that for the second week the residual contracture attributable to collateral ligaments and capsule. The occasional deterioration in the angle is usually the result of the plaster splint becoming soft. Obvious oedema of the finger was noted only in the 2 cases which produced pressure changes.

Our early observations have not shown that the method has any significant effect on capsular contractures, which have therefore not been included in this series; similarly, fibrous ankylosis is not improved by this treatment. A comparison between hydrotherapy and the
TABLE 2

\begin{tabular}{|c|c|c|c|c|c|c|}
\hline & \multirow{2}{*}{\multicolumn{2}{|c|}{ Hydrotherapy }} & \multicolumn{4}{|c|}{ Kolumban's series } \\
\hline & & & $\begin{array}{r}\text { Sto } \\
\text { splin }\end{array}$ & $\begin{array}{l}\text { ic } \\
\text { ing }\end{array}$ & $\begin{array}{l}\text { Dyna } \\
\text { splint }\end{array}$ & $\begin{array}{l}\text { inic } \\
\text { ing }\end{array}$ \\
\hline & Mean & S.D. & Mean & S.D. & Mean & S.1). \\
\hline & 14.8 & & $(6.59)$ & 7.6() & 4.57 & 3.98 \\
\hline Second week & $2 \cdot 2.2$ & 10.3 & 9.60 & 8.60 & 6.37 & 5.19 \\
\hline
\end{tabular}

conventional oil massage, wax therapy, and daily splinting is very difficult. The problem of determining the relative importance of the skin, capsule, and joint in the formation of the contracture is well known. A rough comparison is made below with the figures obtained by Kolumban* in a very careful study of the effect of passive and dynamic splints in contracted fingers. The fingers were exercised for 10 min, then placed in a wax bath, and finally splinted by one of the 2 methods. His mean readings are compared with our mean readings in Table 2. It is, of course, not a valid comparison since there has been no attempt to standardize our sample against that reported by Kolumban. This comparison is, therefore, only in the nature of a preliminary feeler and we are planning to compare these treatments with the assistance of the more sophisticated methods used by Kolumban who has standardized the angle measurements by the use of a "resiliometer" designed by himself. This has enabled him to record angles with great accuracy, whereas the method of assessment which depends on the assessor's passive extension is fraught with error, and in our experience, accurate only within $5^{\circ}$.

\section{CONCLUSION}

Hydrotherapy is a logical method of treatment in contractures of the skin in sweatless fingers. It is inexpensive and since the treatments have only to be given on alternate days it is also timesaving. The danger of pressure effects due to too rapid improvement during a single treatment should be guarded against by applying the splints with a very moderate extension force. Further study is necessary to determine the scope and value of this treatment. 


\section{SUMMARY}

Hydrotherapy is suggested as a means of releasing contractures of the fingers in leprosy patients. It is very rapid in its effect, and therefore there is some danger of pressure sores developing from the too rapid improvement. The method of action of hydrotherapy is discussed and compared with other data in respect of its efficacy.

\section{ACKNOWLEDGEMENTS}

I wish to thank the Leprosy Mission for permission to publish this work, Mr. Walter
Anthony for his technical assistance, $\mathrm{Mr}$. Samuel Kanagarajan for his statistical assistance and Mr. K. Jesudhas for typing the manuscript.

\section{REFERENCES}

HARRIS, J. R. and BRowne, S. G. (1966). The management of dry skin in leprosy patients. Br. med. .J. $i$, 1011 .

Kolumban, s.L. (19). An investigation of the effects of static and dynamic splinting. Submitted to New York University as part of requirement; for M.A. thesis.

THEIN, RUTH E. (1963). In Leprosy in Theory and Practice, 2nd ed., pp. 537-558. Ed. R. G. Cochrane and David. Bristol: John W'right. 